\title{
Role of Balloon Guide Catheter in Modern Endovascular Thrombectomy
}

\author{
Ju-Yu Chueh, ${ }^{1, *}$ Dong-Hun Kang, ${ }^{2, *}$ Byung Moon Kim, ${ }^{3}$ Matthew J. Gounis ${ }^{1}$ \\ Department of Radiology, New England Center for Stroke Research, University of Massachusetts Medical School, Worcester, MA, USA \\ Department of Neurosurgery and Radiology, ${ }^{2}$ School of Medicine, Kyungpook National University, Daegu, Korea \\ Department of Radiology, ${ }^{3}$ Severance Stroke Center, Severance Hospital, Yonsei University College of Medicine, Seoul, Korea
}

Proximal flow control achieved with a balloon guide catheter (BGC) during endovascular treatment of acute ischemic stroke is reviewed in this article. In clinical practice, BGCs offer a multi-faceted approach for clot retrieval by creating proximal flow arrest, reducing embolic burden, and shortening procedure time. Evaluation of frontline thrombectomy procedures with BGCs revealed advantages of combined use over the conventional guide catheter (CGC), notably in the significant reduction of distal emboli to both the affected and previously unaffected territories. Recently, new measures of early and complete reperfusion at first thrombectomy pass have been identified as independent predictors of improved outcomes, which were consistently demonstrated with use of $B G C$ as a safe and effective option to minimize number of passes during intervention. Prior randomized controlled trials reported the positive correlation between BGC-treated patients and a lower risk of mortality as well as shortened procedure time. While BGC use is more common in stent retriever-mediated mechanical thrombectomy, preliminary data has shown the potential benefit of device application during contact aspiration thrombectomy to achieve successful recanalization. However, the question of which major endovascular strategy reigns superior as a frontline remains to be answered. Along with clinical case assessments, BGC performance during in-vitro simulation was analyzed to further understand mechanisms for optimization of thrombectomy technique.

Key Words : Acute stroke · Balloon occlusion · Endovascular thrombectomy · Thrombectomy.

\section{INTRODUCTION}

Rapid evolution in endovascular management of acute large vessel occlusion (LVO) over the past 20 years has enabled neurointerventionalists to offer effective reperfusion treatments to properly selected patients. Evolving endovascular techniques for use in cases of acute LVO include intra-arterial fi- brinolysis, ultrasound-enhanced fibrinolysis, retrievers, contact aspiration with (and later without) catheter debulking separators, and stent-retriever ${ }^{50,56)}$. Recently, stent retrievermediated mechanical thrombectomy (SR-MT) is considered the standard-of-care for selected patients with acute LVO in the anterior circulation due to positive results of recent five randomized clinical trials (RCT) $)^{2,4,16,22,52)}$. A Direct Aspiration

- Received : May 9, 2019 •Revised : June 14, 2019 •Accepted : June 21, 2019

- Address for reprints : Matthew J. Gounis

Department of Radiology, New England Center for Stroke Research, University of Massachusetts Medical School, 55 Lake Avenue North, SA-107R Worcester, MA 01655, USA Tel : +1-508-856-1884, Fax : +1-508-856-1882, E-mail : matthew.gounis@umassmed.edu, ORCID : https://orcid.org/0000-0002-8034-2785

*Chueh J.Y. and Kang D.H. are equally contributed in this paper.

This is an Open Access article distributed under the terms of the Creative Commons Attribution Non-Commercial License (http://creativecommons.org/licenses/by-nc/4.0) which permits unrestricted non-commercial use, distribution, and reproduction in any medium, provided the original work is properly cited. 
First Pass Technique (ADAPT) or contact aspiration thrombectomy (CAT) using large bore catheters is also employed as another frontline treatment for $\mathrm{LVO}^{12,24,32)}$. During the evolution of thrombectomy strategies, the versatile uses of $8 \mathrm{~F}$ or 9 F balloon guide catheters (BGC) in different clinical setups have been recognized as BGCs can be paired with a single clot retriever system ${ }^{23,48}$ or combined with other adjunctive thrombectomy procedures ${ }^{15,37,39)}$.

Clot fragmentation is an inevitable consequence of mechanical thrombectomy. Although fragments are generated throughout the procedure, the largest single contributor to distal emboli during SR-MT is associated with bringing the device and embedded clot into a receiver, namely a catheter. Since the majority of the clot remains on the outside of the device $^{(3)}$, the clot is sheared off the device as it enters the receiver. Inflation of the BGC causes a momentary blockage of antegrade blood flow during SR-MT. Direct aspiration through the BGC during retrieval, or simply removing the rotating hemostatic valve while withdrawing the SR leads to flow reversal at the tip of the BGC allowing the sheared fragments to be removed from the circulation. Regarding the use of BGC during ADAPT, there is a concern about the compromised efficacy of aspiration due to the limitation of the size of aspiration catheter that can be used with the limited inner diameter of the BGC. However, in real practice, some neurointerventionalists have used BGC during ADAPT and have reported the positive role of BGC compared to $\mathrm{CGCS}^{25,57)}$. In addition to lowering the risk of distal embolization, shorter procedure time and higher rate of first-pass success as well as better clinical outcomes are further benefits of using BGCs versus non-BGCs, which will be discussed later in this paper ${ }^{40,44,64,69)}$.

Potential off-label use of BGCs has been described in the previous clinical cases ${ }^{11,49)}$. Direct aspiration from the cervical internal carotid artery (ICA) through BGC without any other aspiration catheter or stent retriever was found to be effective in removing or reducing extensive clot burden such as terminal carotid T- and L-type occlusions. Although the feasibility of this technique may be limited due to the complexity of the clot characteristics, blood supply from communicating arteries, and the tortuosity of the vasculature, successful BGC aspiration in eligible patients is likely to reduce the large clot burden in a short period of time and allow smooth transition to the subsequent treatment option such as SR-MT. Lastly, for patients with severe carotid stenosis, temporary inflation of a
BGC is helpful for endovascular device delivery, particularly for a distal access catheter to enter a proximal ICA stent lumen as illustrated in a previous case ${ }^{10)}$.

Many neurointerventionalists have been reluctant to use BGCs due to a number of concerns, such as difficulty in handling the device, groin complications in patients who are on anticoagulant drugs, induced occlusion of the feeding artery by the BGCs, and compatibility of BGCs with other devic$\mathrm{es}^{47,54)}$. A recent study retrospectively evaluated the risk of groin complications associated with the use of a large bore BGC or sheath in $472 \mathrm{LVO}$ patients who received mechanical thrombectomy ${ }^{54}$. The results suggested that the rate of large bore sheath-related groin complications was between $0.4 \%$ to $0.8 \%$ and such minimal risk should not dissuade neurointerventionalists from using BGCs.

\section{EVALUATION OF BALLOON GUIDE CATHETER IN EXPERIMENTAL MODELS}

Successful development of in-vitro occlusion models not only makes reproducible simulation of mechanical thrombectomy possible but also provides deeper insight into how current thrombectomy technology can be refined to obtain better clinical outcomes. Measures such as device deliverability, recanalization success, hemodynamic data, and distal embolization can be collected and quantified during the in-vitro BGC-related studies.

The key elements of an in-vitro model system of cerebrovascular occlusion include a patient-specific vascular phantom with collateral circulation, engineered clot analogues, and a flow loop ${ }^{7,14,42,43}$. Different manufacturing processes for neurovascular modeling have been described in previous work ${ }^{9,31,53)}$. The silicone elastomer is often selected as a base material for constructing vascular replicas due to its high transparency and the similar stress-strain relationship to the human cerebral vessel from postmortem examination at low stretch ${ }^{9}$. The transparent silicone vascular replica and radiopaque clots allow visualization of clot-device interaction during mechanical thrombectomy. For example, clot shear-off from the stent retriever was observed previously in both the in-vitro (Fig. 1) and in-vivo studies during the BGC assisted SR-MT when the stent retriever was retracted ${ }^{17}$. Parts of the clot were found dislodged and accumulated at the tip of the BGC, compromising the BGC 

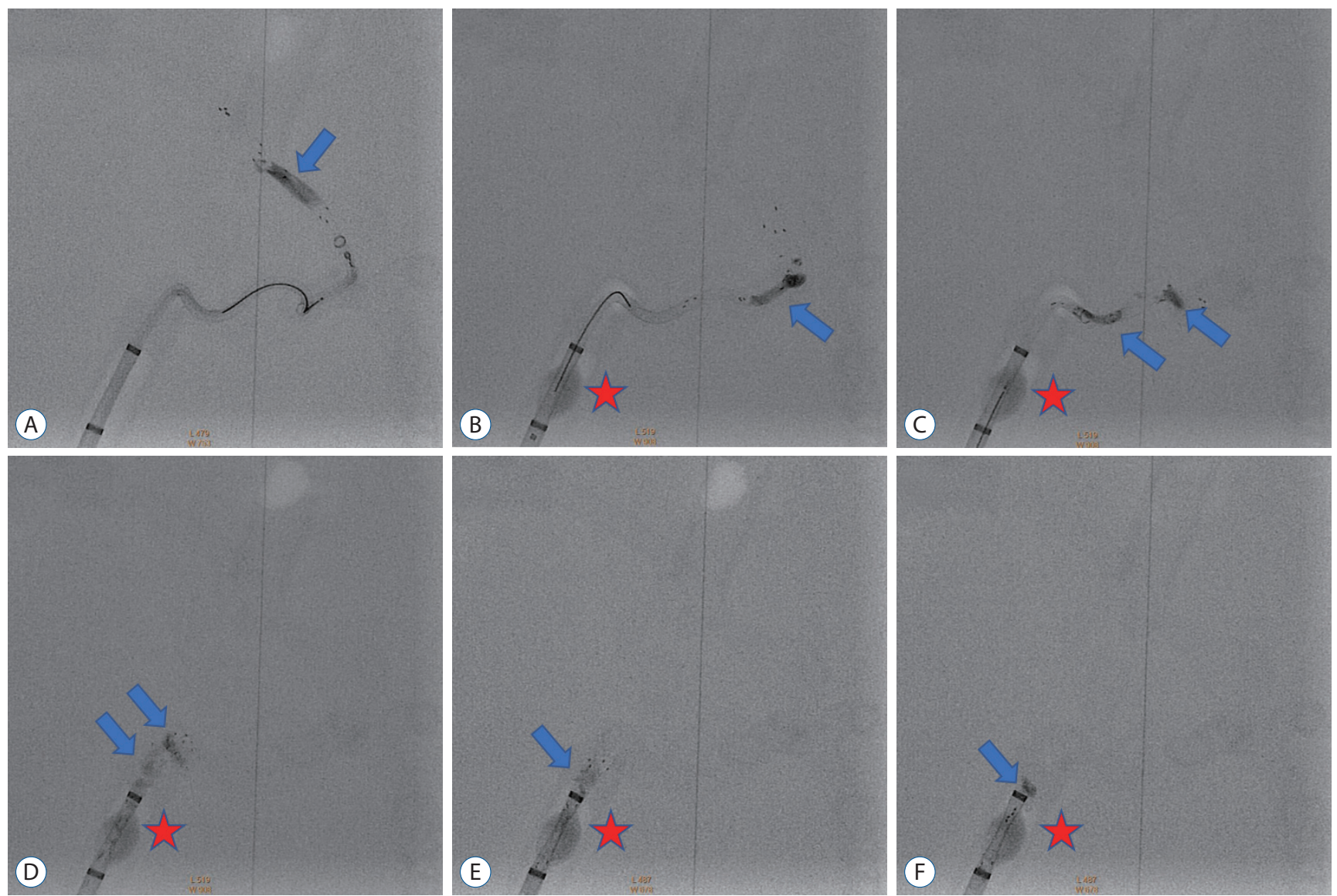

Fig. 1. In-vitro observation of clot shear-off from a stent retriever during mechanical thrombectomy. A : A stent retriever is deployed at the MCA to capture the clot (blue arrow). B-E : Prior to clot retrieval, the balloon is inflated (red star) to arrest the ICA flow. Clot fragmentation is observed during clot removal (blue arrows) with the balloon inflated (red star). F: Clot shear-off from a stent retriever is noted, resulting in a portion of the clot remaining (blue arrow) at the tip of the BGC (red star). MCA : middle cerebral artery, ICA : internal carotid artery, BGC: balloon guide catheter.

aspiration efficacy. Identifying such a problem preclinically can help improve the thrombectomy technique and reduce the risk of distal embolization.

Occurrence of embolic shower is one of the undesirable effects of the SR-MT and is technically modifiable. A study with a total of 144 LVO patients enrolled between 2009 and 2011 reported that embolic events happened in $12.5 \%$ (18/144) of the patients who received SR-MT and were associated with a higher rate of mortality compared to those with no embolic complications ${ }^{13}$. Interestingly, the incidence of distal emboli or emboli in new territories seems lower in human studies compared to in-vitro bench studies. Detection of distal emboli in an in-vitro setup was achieved by Mokin et al. ${ }^{43}$ via gross observation and high-definition video recording. The results of Mokin's study showed that the occurrence of embolization in new territories was significantly reduced by the BGCs, compared with CGCs ( $p=0.0057)$. However, the emboli size range analyzed in this study was not specified and there were no differences in number of emboli observed in distal territory between BGCs and CGCs $(p=1.0)$.

Another approach for distal emboli characterization was performed by using the Coulter Principle ${ }^{6-8}$. Saline was circulating in an middle cerebral artery (MCA) occlusion model, and effluent from both the MCA and anterior cerebral artery (ACA) was collected during the thrombectomy procedure for particle characterization. When a particle (clot fragment) traveled through the aperture, change in the impedance across the aperture was measured. The pulse height was proportional to the volume of the sensed particle and was converted to an equivalent spherical diameter. Completion of the particle analysis yielded not only the number, but the size of each clot fragment within the $8-1000 \mu \mathrm{m}$ range. For particles sized 

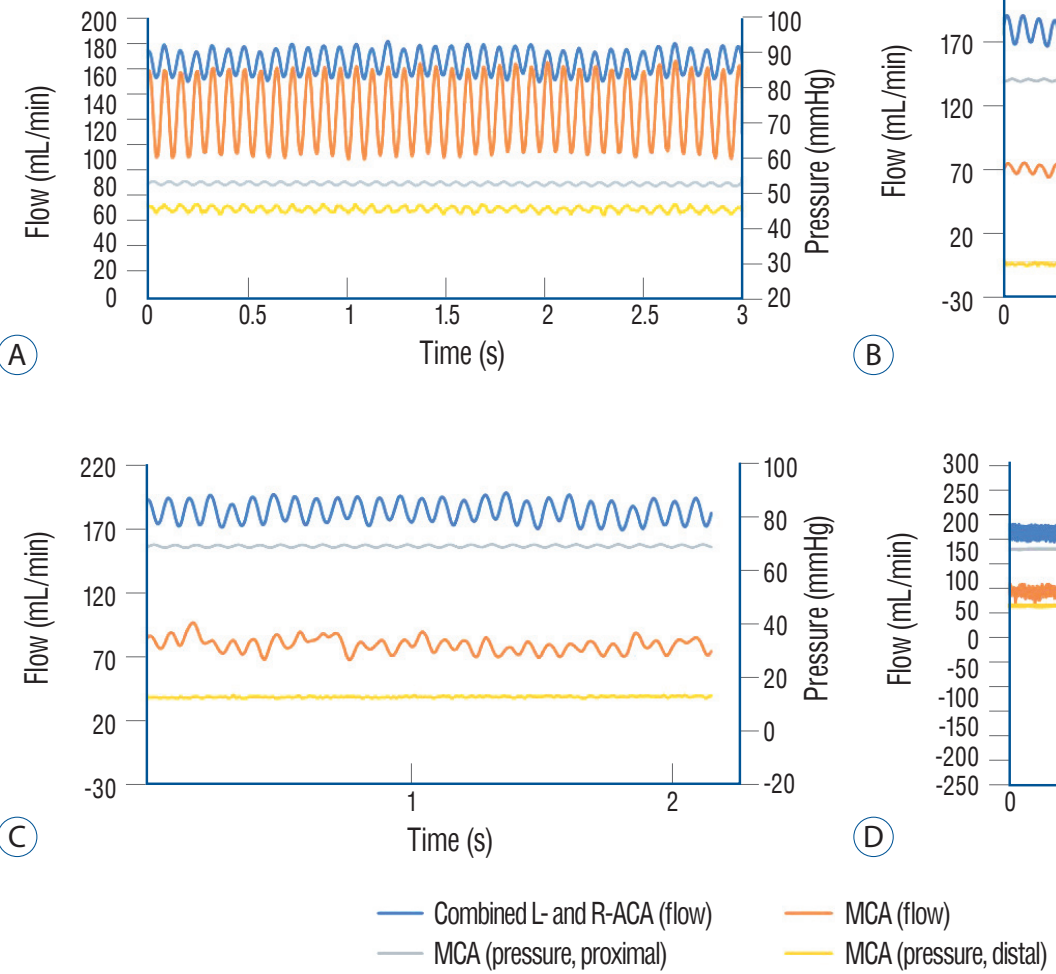
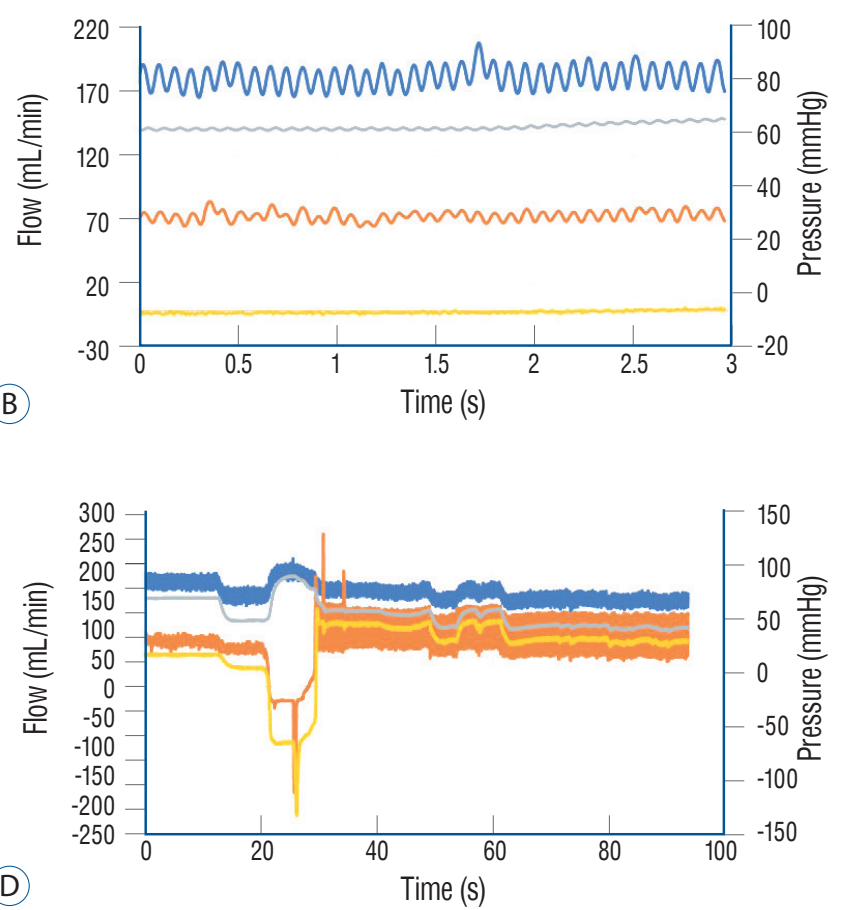

(D)

MCA (pressure, distal)

Fig. 2. Simulation of SR-MT in an in-vitro setup allows real-time measurements of MCA flow and pressure prior to clot introduction (A), after deployment of stent retriever (B), after balloon inflation (C), and during clot retrieval (D). ACA : anterior cerebral artery, SR-MT : stent retriever-mediated mechanical thrombectomy, MCA : middle cerebral artery.

greater than $1 \mathrm{~mm}$, a caliper was used to measure the maximum length of each particle. Prior in-vitro studies using the Coulter Principle for clot measurements found that BGCs significantly reduced the formation of distal emboli when compared to the $\mathrm{CGCs}^{6}$, and the BGC-protected thrombectomy was similar to SR-MT with the Lazarus Cover device (Medtronic Neurovascular, Irvine, CA, USA) in terms of the risk of distal embolization ${ }^{7}$. An important finding from these in-vitro studies was that the majority of the emboli generated during SR-MT are $<20 \mu \mathrm{m}$. To date, brain tolerance to emboli is little known; therefore, the ischemic brain damage related to these small particles is difficult to predict. Further investigation through appropriate selection of animal models and advanced imaging techniques should be considered to address the aforementioned issue.

Blood flow control in the cervical ICA has a great impact on the risk of distal or new territory embolization during SR-MT. Quantification of flow reversal and arrest during balloon inflation have been studied in the in-vitro MCA occlusion mod- els. The quantitative results demonstrate that MCA flow is partially restored (Fig. 2A and B, $73.3 \mathrm{~mL} / \mathrm{min}$ vs. baseline flow of $134.6 \mathrm{~mL} / \mathrm{min}$ ) after deployment of the stent retriever. The presence of the collateral flow keeps the MCA flow constant at $77.9 \mathrm{~mL} / \mathrm{min}$ after BGC inflation (Fig. 2C). During clot retrieval with the balloon inflated, instantaneous pressure changes are recorded at both proximal and distal ends of the clot (Fig. 2D). A recent study further suggested that when BGC is used in combination with large bore aspiration catheters, the efficacy of proximal aspiration via BGC is minimized. As a result, the flow arrest in the ICA can cause reversed flow from the $\mathrm{Al}$ or posterior communicating artery and can to antegrade flow in the M1 segment ${ }^{38)}$.

Most of the experimental models for evaluation of mechanical thrombectomy are embolic occlusion models with a single site of occlusion (e.g., MCA occlusion). Vasospasm, clot-vessel wall interaction as well as various underlying diseases in LVO patients, such as intracranial atherosclerosis, are not incorporated into the in-vitro neurovascular modeling. The absence 
of the abovementioned pathological processes may explain the high recanalization rate observed during the in-vitro simulation of SR-MT and these limitations may be taken into consideration during data interpretation.

\section{BALLOON GUIDE CATHETER IN STENT RE- TRIEVER THROMBECTOMY}

The North American Solitaire Stent Retriever Acute Stroke (NASA) and Trevo Stent-Retriever Acute Stroke (TRACK) registries are two independent post-marketing registries in the United States that assess the effectiveness and clinical outcome of SR-MT in a real-life setting ${ }^{41,44,68)}$. SR-MT was performed in both registries as the frontline technique for vessel recanalization, with the Solitaire stent retriever in NASA and the Trevo device in TRACK. BGC was inflated during the SR-MT to temporarily stop the antegrade flow in the carotid artery, and a similar rate of BGC use was reported in both studies (NASA : $44 \%$ vs. TRACK : 47\%). The results of the NASA registry revealed that in comparison to the non-BGC group, patients with BGC had shorter procedure time, less adjunctive therapy and better clinical outcome at 90 days. BGC was an independent predictor of good clinical outcome, and this finding was also noted in the TRACK registry. Based on those results, the use of BGC had become recommended during SR-MT by the manufacturers of Solitaire stent and Trevo device. One suggested explanation for better outcome with the use of BGC is ischemic conditioning ${ }^{45,55)}$. It is the hypothesis that blockage of the antegrade carotid flow via BGC applies the ischemic stimulus to the vascular bed, resulting in the release of neuroprotective agents that may protect the ischemic tissue and improve the clinical outcome ${ }^{20)}$. However, as previously reviewed, BGC protected thrombectomy reduces the number and size of distal emboli which may alone explain the clinical benefit.

A number of animal and benchtop studies reported that SRMT with BGC reduced the formation of distal emboli; however, surprisingly, there were no significant effects of the BGC use on distal emboli and emboli in new territory in the NASA registry ${ }^{44)}$. A similar finding was noted by Ahn et al. ${ }^{1)}$. Possible explanations for the discrepancy between the experimental and clinical observations include that 1) the micron-sized emboli observed in the in vitro studies are not detectable angiographically and 2) publication bias and heterogeneity across the studies can bias the results ${ }^{1)}$. As of today, there is still a continuing controversy about the use of BGC during mechanical thrombectomy, as reflected in the limited number of cases where BGC is used (approximately 50\% of stroke interventions $)^{3)}$. A series of studies have been done with the aim to understand the effects of BGC on the technique and clinical outcomes for patients who underwent SR-MT ${ }^{3,34,59,64)}$. It was found that patients treated with BGCs had a shorter procedure time, lower number of thrombectomy attempts, lower rates of mortality and higher odds of first-pass recanalization as compared to those treated without BGCs. Achieving a Thrombolysis in Cerebral Infarction (TICI) score of 3 with single thrombectomy pass defines the goal to pursue for future development of thrombectomy devices ${ }^{67)}$. The first-pass effect, an independent predictor of good clinical outcome, has become a new measure of successful mechanical thrombectomy.

Several innovative treatment strategies have been developed based on the combined thromboaspiration and SR-MT technique, such as ARTS, CAPTIVE, CASPER, PROTECT ${ }^{\text {PLus }}$, and $\mathrm{SAVE}^{36-39,58)}$. The concept of combining local aspiration with a stent retriever is to provide continuous and localized suction via a distal intermediate and aspiration catheter from the proximal end of the occlusion during SR-MT. The rationale of providing suction adjacent to the occlusion is to enhance the clot engagement within the stent retriever and withdraw the clot fragments released during initial stent retriever deployment $^{21)}$. In brief, a long sheath or a BGC is placed within the common carotid artery or ICA of the affected side. Subsequently, a large bore aspiration catheter is navigated over a microguidewire (and sometimes a microcatheter) to the level of the occlusion. A stent retriever device, usually Trevo or Solitaire FR, is deployed via a microcatheter. The microcatheter is removed before clot removal to increase cross sectional luminal area and aspiration efficacy of the aspiration catheter ${ }^{46)}$. Suction can be applied via manual aspiration using a $20 \mathrm{~mL}$ or $60 \mathrm{~mL}$ syringe or an aspiration pump. The aspiration catheter serves as a conduit through which the stent retriever along with the clot is removed from the patient. FlowGate (Stryker, Fremont, CA, USA; OD : 8 F, ID : 0.084"), Cello (Medtronic, Irvine, CA, USA; OD : $9 \mathrm{~F}$, ID : 0.085 ” and OD : $8 \mathrm{~F}$, ID : 0.075 ”), Optimo (Tokai, Tokyo, Japan; OD : 9 F , ID : 0.088 ”), 6F Neuron Max (Penumbra, Alameda, CA, USA; OD : 8 F, ID : $\left.0.088^{\prime \prime}\right)$ and 6F Cook Shuttle Sheath (Cook Medical, Bloomington, IN, USA; OD : 8 F, ID : 0.087") are common ancillary 
catheters used with current aspiration catheters. Frequently used aspiration catheters include, but are not limited to, AXS Catalyst $^{\mathrm{TM}} 6$ (Stryker), Sofia ${ }^{\circledR}$ and Sofia ${ }^{\circledR}$ Plus (Microvention, Tustin, CA, USA) and Penumbra ACE ${ }^{\mathrm{TM}}$ (Penumbra).

Slight variations in procedure exist between the ARTS, CAPTIVE, CASPER, PROTECTPLUS and SAVE techniques. One example is the proximal aspiration with the guide catheter proposed in the SAVE method. Another notable difference is that the BGC is used in the ARTS and PROTECTPLUS techniques, whereas the large guiding sheath is recommended for the CAPTIVE, CASPER and SAVE techniques. It should be addressed that limited use of BGC may be due to the size incompatibility between BGCs and the principal chosen technique $^{5}$. Despite these variations, all techniques achieved successful recanalization (modified TICI $\geq 2$ b) in nearly $100 \%$ of the cases, according to the prior retrospective studies. In addition, first-pass modified TICI 3 recanalization was observed in between $43 \%$ to $72 \%$ of the patients, depending on the technique ${ }^{36-39,58)}$. These results are encouraging, although still preliminary, for the development of innovative treatment strategies to benefit patients with acute LVO.

\section{BALLOON GUIDE CATHETER IN CAT}

Based on the results of five RCTs ${ }^{2,4,16,22,52)}$, most stroke guidelines recommend endovascular treatment using SR-MT for acute LVO patients ${ }^{19,51,65)}$. In real practice, however, two major frontline endovascular treatment methods, CAT and SR-MT, are currently used. In a recent survey of U.S. neurointeventionalists, 39.7\% of respondents reported using CAT as frontline therapy followed by $28.2 \%$ opting for SR-MT, and $28.2 \%$ adopting for combined usage of a retrievable stent with aspiration $^{12}{ }^{12}$. Moreover, the Contact Aspiration vs Stent Retriever for Successful Recanalization (ASTER) and COMPASS studies demonstrated that there were no significant differences in the rates of recanalization and good outcomes at 3 months between CAT and SR-MT ${ }^{32,61)}$. Thus, proper designation of casedependent utilization of CAT versus SR-MT remains a challenge for future procedures.

BGC use has been recommended for SR-MT cases in previous RCTs, but not with CAT. Investigations regarding the role of BGC use in CAT are rare because the major group of CAT users (specifically ADAPT users) mostly use a 6 F neuro- sheath as a guiding catheter, usually a Neuron Max (Penumbra ${ }^{60,62)}$. However, given the majority of CAT cases have significant portions of clot outside the tip of the aspiration device ("corked" configuration), there is a risk of shearing the clot off of the aspiration device when entering the receiver, similar to that is occurred using the SR device. Recently, neurointerventionalists have used the BGC and have reported positive results with BGC use during CAT. In one case series consisting of 31 patients with an acute anterior circulation stroke, the authors proposed that the combination of two available methods for preventing distal clot migration, proximal flow arrest via use of a BGC and distal aspiration through a large bore catheter could improve the outcome of the thrombectomy procedure $^{57}$. The 8F Cello BGC (Medtronic) was used for the proximal flow control and the SOFIA catheter (Microvention) was used for the distal aspiration. Mechanical thrombectomy was performed under balloon occlusion of the proximal ICA and simultaneously with continuous distal aspiration, which resulted in a 96.8\% successful recanalization rate (modified TICI $\geq 2 b$ ), with good functional recovery (modified Rankin Scale $0-2$ at 3 months) in $51.6 \%$ of cases.

In addition to the prevention of distal clot migration, recent reviews have suggested another positive effect of BGC use in mechanical thrombectomy ${ }^{28,66)}$. Theoretically, two primary factors determine how much force will be required to retrieve the clot : the impaction force and the combined force of friction and adhesion between the thrombus and the vessel wall. The impaction force is determined by the pressure gradient across the thrombus (Fig. 3). Therefore, lower systemic blood pressure acting on the proximal surface of the thrombus and better retrograde collateral flow on the distal surface of the thrombus will result in a smaller pressure gradient across the occluding thrombus. Inflation of a BGC can markedly reduce the systemic blood pressure acting on the proximal clot face, leading to a decrease in the pressure gradient across the $\operatorname{clot}^{66}$. This can enhance the function of an aspiration catheter in CAT, as well as a stent retriever in SR-MT. The impaction force is also likely to explain the decreased rate of successful recanalization among patients with worse collaterals ${ }^{35}$.

A recent analysis compared data of the $\mathrm{BGC}$ and the CGC groups in frontline CAT cases using a Korean multi-center registry ${ }^{25)}$. In the study, a total of 429 patients were enrolled, with the BGC used in $45.2 \%$ of patients. Compared to the CGC group, BGC use significantly reduced the number of 


$$
55
$$




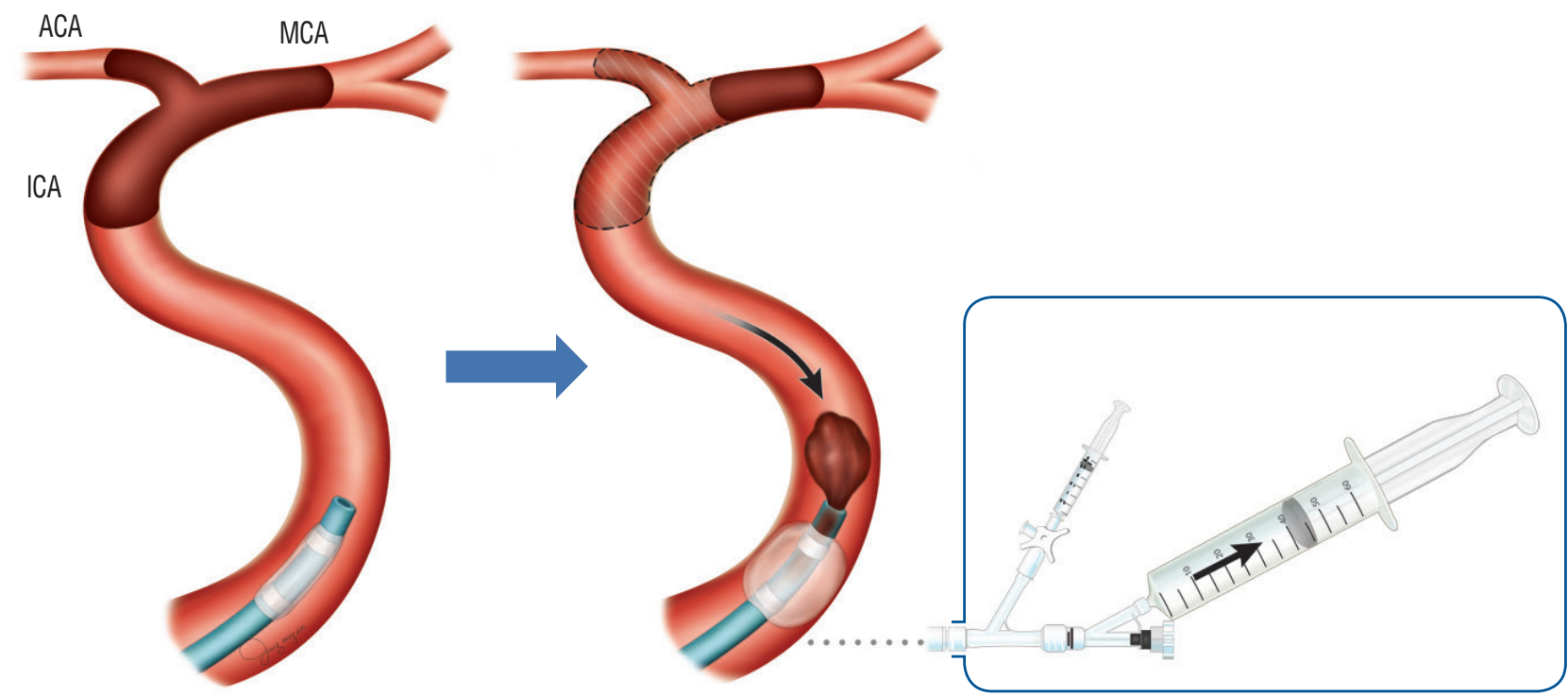

Fig. 4. Illustration of the off-label use of BGC to clot burden reduction in an intra 7 cranial ICA T-type occlusion. Direct manual aspiration using a $60 \mathrm{~mL}$ syringe is performed through an $8 \mathrm{~F}$ or a $9 \mathrm{~F} \mathrm{BGC}$ which was positioned in the proximal ICA to create proximal flow arrest. ACA : anterior cerebral artery, ICA : internal carotid artery, MCA : middle cerebral artery, BGC : balloon guide catheter.

\section{OTHER APPLICATION OF BALLOON GUIDE CATHETER : REMOTE PROXIMAL ASPIRATION WITHOUT CLOT CONTACT}

Despite the rapid evolution of endovascular devices and techniques for recanalization of LVO, mechanical thrombectomy still fails in about a quarter of cases $^{2,4,16,22,52)}$. Extensive burden of the occluding thrombus has been regarded as one of the main etiologies leading to complicated or failed thrombectomy procedures along with anatomical challenges, tandem occlusions, and occlusions with underlying atherosclero$\operatorname{sis}^{29)}$. A larger thrombus burden may complicate the endovascular procedure by requiring more passages with the thrombectomy device leading to a prolonged time to recanalization. Such delays in recanalization can result in larger territory infarctions and a worse functional recovery. Additionally, more extensive thrombi may cause the occlusion of important collateral channels, as the original thrombus itself or migration of the thrombus may pervade noninvolved vascular territories. Off-label use of BGCs has been attempted to remove or reduce the LVO with extensive clot burden ${ }^{11,18,30,49)}$.

One such method involved remote aspiration through the BGC without any clot contact with a catheter or a stent retriever in distal ICA occlusions ${ }^{11}$. During remote aspiration, manual aspiration using a $60 \mathrm{~mL}$ syringe was performed through an $8 \mathrm{~F}$ BGC that was positioned in the cervical carotid vasculature to create proximal flow arrest (Fig. 4), resulting in a significant reduction of the clot burden, which facilitated further intervention leading to full recanalization. Thereafter, a few case reports describing similar BGC use followed ${ }^{18,49)}$. Although the thrombectomy techniques were differently named in each report, such as 'remote aspiration thrombectomy' and 'simple Aspiration with Balloon Catheter (ABC) technique', the fundamentals of the techniques were very similar. One study reported three cases of acute ICA occlusion treated with 'remote aspiration thrombectomy' which was direct manual aspiration with a $60 \mathrm{~mL}$ syringe through a $9 \mathrm{~F}$ BGC in the cervical ICA and resulted in complete recanalization. Another study reported two cases of cardioembolic ICA occlusion that were successfully treated with the simple ABC technique'. This technique also involved simple manual aspiration through an inflated 9 F BGC in the proximal ICA. All the above-mentioned studies demonstrated that the off-label use of the BGC proved useful in removing or reducing the clot burden and was a relatively safe and simple procedure. However, the interpretation of the results should be noted with caution since these technical case reports included a small number of patients. Other variables, such as clot consistency, vessel tortuosity, and the presence of a prominent posterior communicating artery, which can prevent adequate flow ar- 
rest, may also determine the efficacy of the remote aspiration $^{11}$.

A larger case series, which enrolled 86 ICA occlusion patients treated with mechanical thrombectomy during a 5-year period, compared the outcomes of endovascular strategies with or without the use of direct manual aspiration through a BGC at the cervical ICA ${ }^{30)}$. Although in this series, the maneuver was referred to as 'proximal aspiration thrombectomy (PAT)', but the technique was similar to the previously mentioned techniques. In phase 1 of the study, standard thrombectomy without PAT was used for removal of the ICA occlusions ( $n=33$ ). In phase 2, PAT was initially used, followed by the standard thrombectomy for any remaining occlusion $(n=53)$. The authors defined 'responders' as patients who had part of the clot retrieved by PAT with partial or full recanalization achieved. Fifteen of 53 patients $(28.3 \%)$ in phase 2 responded to PAT and the responders had a significantly higher incidence of atrial fibrillation compared to non-responders ( $86.7 \%$ vs. $57.9 \%$; $p=0.046)$. The procedure time was significantly reduced ( 94.5 minutes vs. 56.0 minutes; $p=0.002$ ) and the rate of successful reperfusion was improved (TICI $\geq 2 b$ : $45.5 \%$ vs. $73.6 \%$; $p=0.009$ ) without increasing the incidence of procedure-related complications or intracranial hemorrhage. Overall, off-label use of a BGC seems to reduce clot burden in ICA occlusions. Further investigation in a larger patient cohort will be required to confirm the utility and safety of this approach.

\section{CONCLUSION}

With the rapid advancement of endovascular treatment therapy over time, varying thrombectomy techniques are being continuously fine-tuned to deliver the best possible functional outcome for stroke patients. Key procedural features of the BGC include minimization of distal emboli as a result of antegrade flow control, increased rates of first-pass efficacy, and the ability to pair it with adjunctive devices to achieve successful reperfusion. In addition to allowing a shorter duration of intervention, the availability of crossover rescue with BGC as an alternative strategy for failure during CAT is critical for patients with LVO. As SR-MT and CAT are currently recognized as major frontline treatment methods, assessment of SR-MT with use of BGC has been correlated with clinically and angiographically favorable outcomes. However, limited evidence exists to prove significant benefit of BGC use in combination with distal aspiration. Further evaluation to analyze the role of BGC in CAT may be tested in the in-vitro system of cerebrovascular occlusion, which is necessary to determine potential clinical usefulness of the technique. With the first-pass effect now considered the benchmark of successful thrombectomy, focus of future study should aim to explore the capability of BGCs to lower the rate of adverse events, maximize the number of TICI 3 cases, and reduce the number of thrombectomy attempts during clot retrieval.

\section{CONFLICTS OF INTEREST}

JYC: Consultant for InNeuroCo and Stryker Neurovascular. MJG: Has been a consultant on a fee-per-hour basis for Cerenovus, Imperative Care, Medtronic Neurovascular, Mivi Neurosciences, Phenox, Route 92 Medical, Stryker Neurovascular; holds stock in Imperative Care and Neurogami; and has received research support from the Research support from the National Institutes of Health (NIH), the United States - Israel Binational Science Foundation, Anaconda, Cerenovus, Cook Medical, Gentuity, Imperative Care, InNeuroCo, Insera Therapeutics, Magneto, Microvention, Medtronic Neurovascular, MIVI Neurosciences, Neuravi, Neurogami, Philips Healthcare, Rapid Medical, Route 92 Medical, Stryker Neurovascular, Syntheon, and the Wyss Institute.

\section{INFORMED CONSENT}

This type of study does not require informed consent.

\section{AUTHOR CONTRIBUTIONS}

\author{
Writing - original draft : JYC, DHK \\ Writing - review \& editing : BMK, MJG
}

\section{References}

1. Ahn JH, Cho SS, Kim SE, Kim HC, Jeon JP. The effects of balloon-guide 
catheters on outcomes after mechanical thrombectomy in acute ischemic strokes : a meta-analysis. J Korean Neurosurg Soc 62 : 389397, 2019

2. Berkhemer $O A$, Fransen $P S$, Beumer $D$, van den Berg LA, Lingsma HF, Yoo AJ, et al. : A randomized trial of intraarterial treatment for acute ischemic stroke. N Engl J Med 372 : 11-20, 2015

3. Brinjikji W, Starke RM, Murad MH, Fiorella D, Pereira VM, Goyal M, et al. : Impact of balloon guide catheter on technical and clinical outcomes: a systematic review and meta-analysis. J Neurointerv Surg $10: 335$ 339, 2018

4. Campbell BC, Mitchell PJ, Kleinig TJ, Dewey HM, Churilov L, Yassi N, et al. : Endovascular therapy for ischemic stroke with perfusion-imaging selection. N Engl J Med 372 : 1009-1018, 2015

5. Chalumeau V, Blanc R, Redjem H, Ciccio G, Smajda S, Desilles JP, et al. : Anterior cerebral artery embolism during thrombectomy increases disability and mortality. J Neurointerv Surg 10 : 1057-1062, 2018

6. Chueh JY, Kühn AL, Puri AS, Wilson SD, Wakhloo AK, Gounis MJ : Reduction in distal emboli with proximal flow control during mechanical thrombectomy: a quantitative in vitro study. Stroke 44 : 1396-1401, 2013

7. Chueh JY, Puri AS, Gounis MJ : An in vitro evaluation of distal emboli following lazarus cover-assisted stent retriever thrombectomy. J Neurointerv Surg 9 : 183-187, 2017

8. Chueh JY, Puri AS, Wakhloo AK, Gounis MJ : Risk of distal embolization with stent retriever thrombectomy and adapt. J Neurointerv Surg 8 : 197-202, 2016

9. Chueh JY, Wakhloo AK, Gounis MJ : Neurovascular modeling: smallbatch manufacturing of silicone vascular replicas. AJNR Am J Neuroradiol 30 : 1159-1164, 2009

10. Demerath T, Reinhard M, Elsheikh S, Keuler A, Urbach H, Meckel S : Balloon guide catheter in complex anterior circulation mechanical thrombectomy: beyond proximal occlusion and flow reversal. Clin Neuroradiol $26: 369-373,2016$

11. Eesa M, Almekhlafi MA, Mitha AP, Wong JH, Goyal M : Manual aspiration thrombectomy through balloon-tipped guide catheter for rapid clot burden reduction in endovascular therapy for ICA L/T occlusion. Neuroradiology 54 : 1261-1265, 2012

12. Fargen KM, Arthur AS, Spiotta AM, Lena J, Chaudry I, Turner RD, et al. : A survey of neurointerventionalists on thrombectomy practices for emergent large vessel occlusions. J Neurointerv Surg 9 : 142-146, 2017

13. Gascou G, Lobotesis K, Machi P, Maldonado I, Vendrell JF, Riquelme $C$, et al. : Stent retrievers in acute ischemic stroke: complications and failures during the perioperative period. AJNR Am J Neuroradiol 35 : 734-740, 2014

14. Gilvarry $M$, Vale $D$ : The role of in-vitro modeling in addressing challenging occlusions. J Neurointerv Surg 8 : A93, 2016

15. Goto S, Ohshima T, Ishikawa K, Yamamoto T, Shimato S, Nishizawa T, et al. : A stent-retrieving into an aspiration catheter with proximal balloon (asap) technique: a technique of mechanical thrombectomy. World Neurosurg 109 : e468-e475, 2018

16. Goyal M, Demchuk AM, Menon BK, Eesa M, Rempel JL, Thornton J, et al. : Randomized assessment of rapid endovascular treatment of ischemic stroke. N Engl J Med 372 : 1019-1030, 2015

17. Gralla J, Schroth G, Remonda L, Nedeltchev K, Slotboom J, Brekenfeld C : Mechanical thrombectomy for acute ischemic stroke: thrombus-device interaction, efficiency, and complications in vivo. Stroke 37 : 3019 3024, 2006

18. Haussen DC, Bouslama M, Grossberg JA, Nogueira RG : Remote aspiration thrombectomy in large vessel acute ischemic stroke. J Neurointerv Surg $9: 250-252,2017$

19. Hong KS, Ko SB, Yu KH, Jung C, Park SQ, Kim BM, et al. : Update of the Korean clinical practice guidelines for endovascular recanalization therapy in patients with acute ischemic stroke. J Stroke 18 : 102-113, 2016

20. Hougaard KD, Hjort N, Zeidler D, Sørensen L, Nørgaard A, Hansen $T M$, et al. : Remote ischemic perconditioning as an adjunct therapy to thrombolysis in patients with acute ischemic stroke: a randomized trial. Stroke 45 : 159-167, 2014

21. Humphries W, Hoit D, Doss VT, Elijovich L, Frei D, Loy D, et al. : Distal aspiration with retrievable stent assisted thrombectomy for the treatment of acute ischemic stroke. J Neurointerv Surg 7 : 90-94, 2015

22. Jovin TG, Chamorro A, Cobo E, de Miquel MA, Molina CA, Rovira A, et al. : Thrombectomy within 8 hours after symptom onset in ischemic stroke. N Engl J Med 372 : 2296-2306, 2015

23. Kammerer S, du Mesnil de Rochemont R, Wagner M, You SJ, Tritt S, Mueller-Eschner $M$, et al. : Efficacy of mechanical thrombectomy using stent retriever and balloon-guiding catheter. Cardiovasc Intervent Radiol 41 : 699-705, 2018

24. Kang DH, Hwang YH : Frontline contact aspiration treatment for emergent large vessel occlusion: a review focused on practical techniques. J Stroke 21 : 10-22, 2019

25. Kang DH, Kim BM, Heo JH, Nam HS, Kim YD, Hwang YH, et al. : Effect of balloon guide catheter utilization on contact aspiration thrombectomy. J Neurosurg, 2018 [Epub ahead of print]

26. Kang DH, Kim JW, Kim BM, Heo JH, Nam HS, Kim YD, et al. : Need for rescue treatment and its implication: stent retriever versus contact aspiration thrombectomy. J Neurointerv Surg, 2019 [Epub ahead of print]

27. Kang DH, Kim YW, Hwang YH, Park J, Hwang JH, Kim YS : Switching strategy for mechanical thrombectomy of acute large vessel occlusion in the anterior circulation. Stroke $44: 3577-3579,2013$

28. Kang DH, Park J : Endovascular stroke therapy focused on stent retriever thrombectomy and direct clot aspiration: historical review and modern application. J Korean Neurosurg Soc 60 : 335-347, 2017

29. Kim BM : Causes and solutions of endovascular treatment failure. J Stroke 19 : 131-142, 2017

30. Kim YW, Kang DH, Hwang YH, Park J, Kim YS : Efficacy of proximal aspiration thrombectomy for using balloon-tipped guide catheter in acute intracranial internal carotid artery occlusion. J Korean Neurosurg Soc 59 : 379-384, 2016

31. Knox K, Kerber CW, Singel SA, Bailey MJ, Imbesi SG : Rapid prototyping to create vascular replicas from ct scan data: making tools to teach, rehearse, and choose treatment strategies. Catheter Cardiovasc 
Interv 65 : 47-53, 2005

32. Lapergue B, Blanc R, Gory B, Labreuche J, Duhamel A, Marnat G, et al. : Effect of endovascular contact aspiration vs stent retriever on revascularization in patients with acute ischemic stroke and large vessel occlusion: the ASTER randomized clinical trial. JAMA 318 : 443-452, 2017

33. Lapergue B, Blanc R, Guedin P, Decroix JP, Labreuche J, Preda C, et al. : A direct aspiration, first pass technique (ADAPT) versus stent retrievers for acute stroke therapy: an observational comparative study. AJNR Am J Neuroradiol 37 : 1860-1865, 2016

34. Lee DH, Sung JH, Kim SU, Yi HJ, Hong JT, Lee SW : Effective use of balloon guide catheters in reducing incidence of mechanical thrombectomy related distal embolization. Acta Neurochir (Wien) 159 : 1671-1677, 2017

35. Liebeskind DS, Jahan R, Nogueira RG, Zaidat 00, Saver JL; SWIFT Investigators : Impact of collaterals on successful revascularization in solitaire fr with the intention for thrombectomy. Stroke 45 : 2036-2040, 2014

36. Maegerlein C, Berndt MT, Mönch S, Kreiser K, Boeckh-Behrens T, Lehm $M$, et al. : Further development of combined techniques using stent retrievers, aspiration catheters and BGC : the PROTECTPLUStechnique. Clin Neuroradiol, 2018 [Epub ahead of print]

37. Massari F, Henninger N, Lozano JD, Patel A, Kuhn AL, Howk M, et al. : Arts (aspiration-retriever technique for stroke): initial clinical experience. Interv Neuroradiol 22 : 325-332, 2016

38. Maus V, Behme D, Kabbasch C, Borggrefe J, Tsogkas I, Nikoubashman 0 , et al. : Maximizing first-pass complete reperfusion with save. Clin Neuroradiol $28: 327-338,2018$

39. McTaggart RA, Tung EL, Yaghi S, Cutting SM, Hemendinger M, Gale HI, et al. : Continuous aspiration prior to intracranial vascular embolectomy (CAPTIVE): a technique which improves outcomes. J Neurointerv Surg 9 : 1154-1159, 2017

40. Menon BK, Sajobi TT, Zhang Y, Rempel JL, Shuaib A, Thornton J, et al. : Analysis of workflow and time to treatment on thrombectomy outcome in the endovascular treatment for small core and proximal occlusion ischemic stroke (ESCAPE) randomized, controlled trial. Circulation 133 : 2279-2286, 2016

41. Mokin M, Abou-Chebl A, Castonguay AC, Nogueira RG, English JD, Farid $H$, et al. : Real-world stent retriever thrombectomy for acute ischemic stroke beyond 6 hours of onset: analysis of the nasa and track registries. J Neurointerv Surg 11 : 334-337, 2019

42. Mokin M, lonita CN, Nagesh SV, Rudin S, Levy El, Siddiqui AH : Primary stentriever versus combined stentriever plus aspiration thrombectomy approaches: in vitro stroke model comparison. J Neurointerv Surg 7 : 453-457, 2015

43. Mokin M, Setlur Nagesh SV, Ionita CN, Levy El, Siddiqui AH : Comparison of modern stroke thrombectomy approaches using an in vitro cerebrovascular occlusion model. AJNR Am J Neuroradiol 36 : 547-551, 2015

44. Nguyen TN, Malisch T, Castonguay AC, Gupta R, Sun CH, Martin CO, et al. : Balloon guide catheter improves revascularization and clinical outcomes with the solitaire device: analysis of the north american solitaire acute stroke registry. Stroke 45 : 141-145, 2014
45. Nguyen TN, Malisch TW, Zaidat 00; North American Solitaire Acute Stroke Registry : Response to letter regarding article, "balloon guide catheter improves revascularization and clinical outcomes with the solitaire device: analysis of the north american solitaire acute stroke registry". Stroke 45 : e86, 2014

46. Nikoubashman O, Alt JP, Nikoubashman A, Büsen M, Heringer S, Brockmann $C$, et al. : Optimizing endovascular stroke treatment: removing the microcatheter before clot retrieval with stent-retrievers increases aspiration flow. J Neurointerv Surg 9 : 459-462, 2017

47. Nikoubashman O, Wischer D, Hennemann HM, Sandmann J, Sichtermann T, Müschenich FS, et al. : Balloon-guide catheters are needed for effective flow reversal during mechanical thrombectomy. AJNR Am J Neuroradiol 39 : 2077-2081, 2018

48. Oh JS, Yoon SM, Shim JJ, Doh JW, Bae HG, Lee KS : Efficacy of balloonguiding catheter for mechanical thrombectomy in patients with anterior circulation ischemic stroke. J Korean Neurosurg Soc 60 : 155-164, 2017

49. Okamura A, Kuroki K, Shinagawa K, Yamada N : Simple aspiration with balloon catheter technique (simple $A B C$ technique) against proximal internal carotid artery occlusion in cases of cardiogenic cerebral embolism. Interv Neuroradiol 24 : 317-321, 2018

50. Pierot $L$, Soize $S$, Benaissa A, Wakhloo AK : Techniques for endovascular treatment of acute ischemic stroke: from intra-arterial fibrinolytics to stent-retrievers. Stroke 46 : 909-914, 2015

51. Powers WJ, Derdeyn CP, Biller J, Coffey CS, Hoh BL, Jauch EC, et al. : 2015 American Heart Association/American Stroke Association focused update of the 2013 guidelines for the early management of patients with acute ischemic stroke regarding endovascular treatment: a guideline for healthcare professionals from the American Heart Association/American Stroke Association. Stroke 46 : 3020-3035, 2015

52. Saver JL, Goyal M, Bonafe A, Diener HC, Levy El, Pereira VM, et al. : Stent-retriever thrombectomy after intravenous t-PA vs. t-PA alone in stroke. N Engl J Med 372 : 2285-2295, 2015

53. Seong J, Sadasivan C, Onizuka M, Gounis MJ, Christian F, Miskolczi L, et al. : Morphology of elastase-induced cerebral aneurysm model in rabbit and rapid prototyping of elastomeric transparent replicas. Biorheology 42 : 345-361, 2005

54. Shah VA, Martin CO, Hawkins AM, Holloway WE, Junna S, Akhtar N : Groin complications in endovascular mechanical thrombectomy for acute ischemic stroke: a 10-year single center experience. J Neurointerv Surg $8: 568-570,2016$

55. Simonsen CZ, Sørensen LH, Andersen G : Letter by simonsen et al Regarding article, "balloon guide catheter improves revascularization and clinical outcomes with the solitaire device: analysis of the north american solitaire acute stroke registry". Stroke 45 : e85, 2014

56. Smith WS, Furlan AJ : Brief history of endovascular acute ischemic stroke treatment. Stroke 47 : e23-e26, 2016

57. Stampfl S, Pfaff J, Herweh C, Pham M, Schieber S, Ringleb PA, et al. : Combined proximal balloon occlusion and distal aspiration: a new approach to prevent distal embolization during neurothrombectomy. J Neurointerv Surg 9 : 346-351, 2017 
58. Stapleton CJ, Leslie-Mazwi TM, Torok CM, Hakimelahi R, Hirsch JA, Yoo AJ, et al. : A direct aspiration first-pass technique vs stentriever thrombectomy in emergent large vessel intracranial occlusions. J Neurosurg $128: 567-574,2018$

59. Teleb MS : Endovascular acute ischemic stroke treatment with flowgate balloon guide catheter: a single-center observational study of flowgate balloon guide catheter use. Interv Neurol 7 : 327-333, 2018

60. Turk AS, Frei D, Fiorella D, Mocco J, Baxter B, Siddiqui A, et al. : ADAPT FAST study: a direct aspiration first pass technique for acute stroke thrombectomy. J Neurointerv Surg 6 : 260-264, 2014

61. Turk AS, Siddiqui A, Fifi JT, De Leacy RA, Fiorella DJ, Gu E, et al. : Aspiration thrombectomy versus stent retriever thrombectomy as first-line approach for large vessel occlusion (COMPASS): a multicentre, randomised, open label, blinded outcome, non-inferiority trial. Lancet 393 : 998-1008, 2019

62. Turk AS, Spiotta A, Frei D, Mocco J, Baxter B, Fiorella D, et al. : Initial clinical experience with the ADAPT technique: a direct aspiration first pass technique for stroke thrombectomy. J Neurointerv Surg 6 : 231237, 2014

63. van der Marel K, Chueh JY, Brooks OW, King RM, Marosfoi MG, Langan ET, et al. : Quantitative assessment of device-clot interaction for stent retriever thrombectomy. J Neurointerv Surg 8 : 1278-1282, 2016
64. Velasco A, Buerke B, Stracke CP, Berkemeyer S, Mosimann PJ, Schwindt $W$, et al. : Comparison of a balloon guide catheter and a non-balloon guide catheter for mechanical thrombectomy. Radiology 280 : 169176, 2016

65. Wahlgren N, Moreira T, Michel P, Steiner T, Jansen O, Cognard C, et al. : Mechanical thrombectomy in acute ischemic stroke: consensus statement by ESO-Karolinska Stroke Update 2014/2015, supported by ESO, ESMINT, ESNR and EAN. Int J Stroke 11 : 134-147, 2016

66. Yoo AJ, Andersson T : Thrombectomy in acute ischemic stroke: challenges to procedural success. J Stroke $19:$ 121-130, 2017

67. Zaidat 00, Castonguay AC, Linfante I, Gupta R, Martin CO, Holloway $W E$, et al. : First pass effect: a new measure for stroke thrombectomy devices. Stroke 49 : 660-666, 2018

68. Zaidat 00, Castonguay AC, Nogueira RG, Haussen DC, English JD, Satti $S R$, et al. : Trevo stent-retriever mechanical thrombectomy for acute ischemic stroke secondary to large vessel occlusion registry. J Neurointerv Surg 10 : 516-524, 2018

69. Zaidat OO, Mueller-Kronast NH, Hassan AE, Haussen DC, Jadhav AP, Froehler MT, et al. : Impact of balloon guide catheter use on clinical and angiographic outcomes in the stratis stroke thrombectomy registry.

Stroke 50 : 697-704, 2019 